Data de recebimento do artigo: 2-2-2017 Data de aceite do artigo: $9-5-2018$

\title{
Os reflexos da Lei da Inovação em uma universidade federal do estado do Rio Grande do Sul (RS)
}

\author{
Ana Paula Perlin \\ Doutoranda no Programa de Pós-graduação em Administração da Universidade Federal de Santa \\ Maria (UFSM). E-mail: anapaula.perlin@yahoo.com.br (Brasil)
}

\section{Clandia Maffini Gomes}

Docente no Departamento de Ciências Administrativas e no Programa de Pós-graduação em Administração da Universidade Federal de Santa Maria (UFSM).

E-mail: clandiamg@gmail.com (Brasil)

\section{Kamila Frizzo}

Mestranda no Programa de Pós-graduação em Administração da Universidade Federal de Santa Maria (UFSM). E-mail: kamila.frizzo@gmail.com (Brasil)

\author{
Gabriela Rossato \\ Graduanda em Administração da Universidade Federal de Santa Maria (UFSM). \\ E-mail: gabi.rossato@hotmail.com (Brasil).
}

\section{RESUMO}

A inovação tecnológica possui um papel importante e de grande influência no desenvolvimento da economia e da sociedade. Os órgãos públicos vêm incentivando e fomentando a inovação tecnológica por meio de políticas e regulamentações como a Lei da Inovação Tecnológica, que dispõe sobre incentivos à inovação e à pesquisa científica e tecnológica no ambiente produtivo. Dessa forma, o presente artigo tem como objetivo central identificar os reflexos da Lei da Inovação em uma Universidade Federal do RS. O estudo se caracteriza como do tipo qualitativo e exploratório. Foi realizado por meio da aplicação de entrevistas semiestruturadas com um gestor da Universidade e três responsáveis pela Agência de Inovação da Universidade. A partir da análise de resultados foi possível observar um fortalecimento da interação entre universidade e empresas e a facilitação nos processos de parcerias e na criação de órgãos responsáveis por essa iteração. No entanto, foi possível verificar que ainda há alguns desafios referentes à Lei da Inovação na Universidade, principalmente relacionado a aspectos operacionais, a falta de conhecimento dos docentes e também algumas barreiras ideológicas. Apesar das dificuldades, os entrevistados acreditam que a Lei da Inovação pode gerar inúmeros benefícios à instituição.

Palavras-chave: Inovação tecnológica. Lei da Inovação. Universidade Federal. 


\title{
The Reflections from the Innovation Law at a Federal University of the State of Rio Grande do Sul (RS)
}

\begin{abstract}
The technological innovation plays an important role and great influence on the development of economy and society. Public agencies have been encouraging and fostering technological innovation through policies and regulations such as the Law of Technological Innovation, which provides incentives for innovation and scientific and technological research in the production environment. Thus this article is mainly aimed to identify the Innovation Law reflections at the Federal University in Rio Grande do Sul (RS). The study is characterized as a case study, being also qualitative and descriptive. It was performed through the application of semi-structured interviews with a university manager and three responsible in the University Innovation Agency. From the analysis results we observed a strengthening of interaction between universities and companies and facilitating the partnership process and the creation of bodies responsible for this interaction. However, we found that there are still some challenges related to Innovation Law at universities, mainly related to operational aspects, the lack of knowledge by the professors and also some ideological barriers. Despite the difficulties, the respondents believe that the Innovation Law can generate numerous benefits for the institution.
\end{abstract}

Keywords: Technological innovation. Innovation Law. Federal University.

\section{Como referenciar em APA:}

Perlin, A. P., Gomes, C. M., Frizzo, K., Rossato, G. (2018). Os Reflexos da Lei da Inovação em uma Universidade Federal do Estado do Rio Grande do Sul (RS). R.G.Secr.,GESEC, 9(3).

\section{Como referenciar em ABNT:}

PERLIN, A. P.; GOMES, C. M.; FRIZZO, K.; ROSSATO, G. Assédio moral no trabalho: a compreensão dos trabalhadores sobre a violência. R.G.Secr.,GESEC, v. 9, n. 3, Dez. 2018.
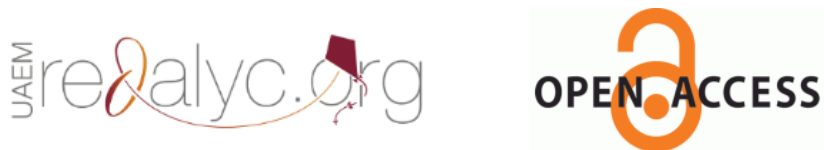


\section{Introdução}

A inovação tecnológica possui um importante papel para o desenvolvimento da economia e da sociedade. O mercado exige que as organizações e regiões se desenvolvam por meio de novas ofertas de produtos e serviços, da implementação de novos modelos de negócios, fundamentados na eficiência, na redução de custos, na minimização dos impactos ambientais aliados à tecnologia.

A inovação tecnológica refere-se às mudanças tecnológicas em produtos (bens ou serviços) oferecidos à sociedade, ou na forma pela qual produtos são criados e oferecidos (Plonski, 2005). Conforme Matias-Pereira e Kruglianskas (2005), o processo de desenvolvimento da inovação tecnológica ainda não refletiu resultados significativos, principalmente no que tange a interação entre a ciência e o setor produtivo.

Nesse sentido, parece que os órgãos governamentais estão atuando na fomentação da inovação tecnológica, sendo uma das principais ações a criação e a aprovação da Lei de incentivo à inovação, à pesquisa científica e tecnológica no ambiente produtivo (Lei Federal $\mathrm{n}^{\mathrm{o}}$ 10.973/2004). Tal lei se constitui na mais importante diretriz governamental para a aproximação dos diversos agentes que compõem o sistema nacional de inovação brasileiro, devendo funcionar como instrumento de suporte para ultrapassar o obstáculo da dependência tecnológica do país (Matias-Pereira e Kruglianskas, 2005).

Corroborando Machado e Rupphental (2014) afirmam que a Lei de Inovação tem como premissa básica estabelecer um conjunto de mecanismos para dar condições ao Brasil de se igualar aos países desenvolvidos, fazendo com que o processo da inovação tecnológica seja desenvolvido desde as Instituições Científicas e Tecnológicas (ICT) até o setor produtivo, envolvendo as empresas por meio da interação de pesquisadores das ICT na iniciativa privada.

Conforme Serzedello e Tomaé (2011), as universidades, parques tecnológicos, institutos tecnológicos e de pesquisa são os principais ambientes de produção tecnológicas no Brasil, pois são espaços que possuem a infraestrutura para desenvolver pesquisa aplicada. As pesquisas aplicadas desenvolvidas nesses ambientes, geralmente, são fundamentadas pelo conhecimento científico, resultante de pesquisa básica, que tem origem nas universidades e assim resultam em produtos e processos denominados produção tecnológica. 
O Estado brasileiro possui um importante papel no que tange as atividades e promoção de ações relacionadas à ciência e tecnologia. A Constituição Federal do Brasil (1988) definiu em grandes linhas, esse papel em diversas atividades, fortalecendo o Estado como articulador, promotor e incentivador, na prática dessas ações. Para Matias-Pereira e Krugliankas (2005), a aprovação da Lei da Inovação, apesar de possuir algumas lacunas, representa um instrumento relevante de apoio às políticas industrial e tecnológica do Brasil.

Visando adequar-se às premissas da Lei de Inovação Tecnológica, a Universidade Federal por meio da Resolução $\mathrm{n}^{\circ}$. 005/2005, de 19 de abril de 2005, criou o Núcleo de Inovação e Transferência de Tecnologia (NIT), ligado a Pró-reitoria de Pós-graduação e Pesquisa, regulamentando a gestão da propriedade intelectual no âmbito da Universidade e definindo a missão e os objetivos do NIT. Em 2015, a Universidade Federal, por meio da Resolução $n^{\circ}$. 001/2015, aprovou a criação da Agência de Inovação e Transferência de Tecnologia, como órgão executivo da Administração Superior, tendo como objetivo a gestão da propriedade intelectual, do empreendedorismo, da transferência de tecnologia e das parcerias envolvendo a universidade, promovendo a sinergia dessas atividades e a disseminação da cultura empreendedora no âmbito da instituição.

Desse modo, o presente estudo tem como objetivo identificar os reflexos da Lei da Inovação em uma Universidade Federal do Estado do Rio Grande do Sul (RS), visando assim, contribuir para o fortalecimento dos estudos relacionados aos seus reflexos nas universidades federais, bem como fomentar o desenvolvimento de estudos organizacionais no Brasil. Ainda se espera cooperar com o fortalecimento de núcleos emergentes e propiciar melhorias em processos nas instituições estudadas.

Este trabalho está estruturado em quatro seções além desta introdução. A segunda corresponde ao referencial bibliográfico, a terceira seção trata dos procedimentos metodológicos do estudo. Logo após, é apresentada a análise e discussão dos resultados, e por fim a quinta seção se refere às considerações finais do estudo.

\section{Inovação Tecnológica e Universidade}

A inovação é fundamental para o processo de evolução de um país, onde a concorrência capitalista aumenta cada vez mais. Como resultado desse desenvolvimento tem- 
se a aceleração da disseminação de tecnologias, o que modificou a relação entre tecnologia, ciência e inovação e favoreceu o avanço do conhecimento (Pacheco, 2010).

De acordo com Reis (2004) a inovação tecnológica pode ser compreendida como um conjunto de ações sistemáticas e coordenadas, na introdução e aplicação do conhecimento para o desenvolvimento e produção de novos produtos e processos produtivos. Além disso, as inovações tecnológicas também podem ser representadas por mudanças tecnológicas com melhoria em alguns atributos de processos, produtos ou serviços já existentes.

Nesse sentido, a grande competitividade dos países desenvolvidos acontece em virtude da crescente e sólida atividade tecnológica. Dessa forma, países em desenvolvimento precisam de mais esforços para se tornarem competitivos e independentes tecnologicamente. Não é obrigatório que as políticas públicas privilegiem unicamente a inovação, mas é essencial uma melhora da estrutura técnica, que possibilite a capacitação em pesquisa e desenvolvimento (Sbragia \& Stal, 2004).

As universidades e empresas parecem se diferenciar quanto ao processo de inovação. Enquanto as universidades não almejam lucro e a implementação da inovação, já que criam o conhecimento para ser levado ao mercado, as empresas implementam e comercializam essa inovação. Além disso, o ambiente nas universidades é propício ao desenvolvimento da pesquisa, visto que possuem um grande número de laboratórios, pesquisadores e amplo acesso às tecnologias, além de disponibilidade de financiamentos para pesquisa. Dessa forma, parece haver a facilitação do relacionamento entre sociedade e governo na solução de problemas e da Lei de Inovação (Gubiani, 2011).

As universidades destacam-se como ambientes impulsionadores de novos produtos e serviços - estas instituições parecem possuir condições básicas para atuarem como agentes de inovação. Conforme define o Modelo Sistêmico de Inovação da OECD e o modelo da tríplice hélice, faz-se necessário criar conhecimento polivalente: básico e tecnológico simultâneo (universidade e empresa em conjunto) (Plonski, 1995; Etzkowitz \& Spivack, 2001; Etzkowitz, 2005; Viale \& Etzkowitz, 2005).

Para Etzkowitz e Webster (1998), o futuro da universidade está ligado ao conhecimento, assim como pela produção de conhecimento e suas implicações sociais. Segundo os autores, como parte de mudanças institucionais, as universidades vêm 
desenvolvendo novos relacionamentos, visto as crescentes exigências da competitividade empresarial.

Dessa forma, quando identificam pesquisas com alto potencial, as universidades fornecem o auxílio necessário para professores e alunos inovarem. Assim, a universidade deve ter a capacidade de interpretar as necessidades da sociedade, criando novos critérios intelectuais e projetos de pesquisa. A universidade detém autonomia, o governo e as empresas são parceiros na produção de novos conhecimentos (Etzkowitz, 2009).

As universidades parecem exercer além da sua função básica, diversos outros papéis na busca pelo desenvolvimento da sociedade. Seu compromisso, além da educação e formação de recursos humanos, abrange também a pesquisa e extensão, além de assegurar o avanço da ciência. No entanto, o deslocamento dos resultados da pesquisa para as empresas é indispensável para garantir o fluxo de informações dentro do Sistema Nacional de Inovação (SNI) (Fujino, Stal \& Plonski, 1999).

Segundo Nelson (1993) um Sistema Nacional de Inovação (SNI) é um grupo articulado de instituições dos setores público e privado que interagem para promover o desenvolvimento científico e tecnológico de um país, sendo a inovação e o aprendizado seus aspectos cruciais. Inclui institutos de pesquisa, universidades, empresas de consultoria, escolas técnicas, empresas industriais, associações empresariais e agências reguladoras, gerando, modificando, adaptando e difundindo ideias inovadoras.

Para Patel e Pavitt (1994), países desenvolvidos possuem SNIs maduros, capazes de mantê-los na fronteira tecnológica internacional. Corroborando Bergerman (2005), discorre que as empresas investem na contratação de cientistas e engenheiros, financiando seus próprios laboratórios e protegem suas inovações por meio do registro de propriedade intelectual.

Segundo Neto (2005), no Brasil, mais de 70\% dos pesquisadores estão dentro das universidades em tempo integral e não possuem experiência profissional. Em comparação com empresas de países desenvolvidos, essa realidade faz com que o nível de inovação nas empresas nacionais seja baixo. Tal resultado parece estar relacionado às baixas colocações do Brasil em índices de competitividade econômica e tecnológica (Bergerman, 2005).

Para Fujino, Stal e Plonski (1999), no caso das universidades brasileiras, apesar do aumento da consciência sobre a necessidade de mostrar à sociedade os resultados da pesquisa financiada com recursos públicos, não existia até então uma política relativa a essa questão, o 
que implica a transferência desses resultados e a sua transformação em inovação por parte das empresas.

Desse modo, parece que os órgãos públicos vêm percebendo a necessidade de interação entre universidades e empresas e seus benefícios para o desenvolvimento econômico. Conforme o Ministério de Ciência, Tecnologia e Inovação (2016) o grande desafio de solidificar no Brasil uma cultura de inovação está relacionado a constatação de que a produção de conhecimento e a inovação tecnológica, são determinantes de políticas de desenvolvimento dos países, o conhecimento parece ser assim o elemento-chave das novas empresas e a inovação é o conceito norteador de transformação econômica e social. Nesse sentido, algumas políticas e legislações foram desenvolvidas visando estimular e fomentar a inovação nas instituições, como é no caso da Lei da Inovação.

A combinação de políticas governamentais e estratégias empresariais cria um ambiente favorável à inovação, que vêm crescendo no Brasil. A procura pelo aumento da competitividade empresarial, levou o governo a criar políticas de incentivo à inovação. Dessa forma, o governo Federal pretende incentivar a inovação por meio de órgãos e agências como a Financiadora de Estudos e Projeto - Finep, Banco Nacional de Desenvolvimento Econômico e Social - BNDES, Ministério de Ciência, Tecnologia e Inovação - MCTI, Coordenação de Aperfeiçoamento de Pessoal de Nível Superior - CAPES e Conselho Nacional de Pesquisas CNPq, assim como de governos estaduais que também aumentaram seus investimentos em inovação (Pacheco, 2010).

Assim, a Lei de Inovação (Lei 10.973/04, regulamentada pelo Decreto 5.563, de 11 de outubro de 2005), "estabelece medidas de incentivo à inovação e à pesquisa científica e tecnológica no ambiente produtivo, com vistas à capacitação tecnológica, ao alcance da autonomia tecnológica e ao desenvolvimento do sistema produtivo nacional e regional do País”. Para estimular a construção de ambientes especializados e inovadores, sugere a geração de um novo marco regulatório, que vise estimular a criação de patentes e o deslocamento de tecnologia das universidades públicas para o setor privado. Na sua elaboração, houve o consenso de que o país precisa incitar o aumento da competitividade das empresas, o que revelaria a inovação (Fujino \& Stal 2005).

De acordo com o Ministério da Ciência, Tecnologia e Inovação (MCTI) (2013), o marco regulatório brasileiro (Lei 10.973/2004), está fundamentado em torno de três vertentes. 
Braga e Filho (2014) apresentam que a primeira vertente trata da constituição de ambiente propício às parcerias estratégicas entre as universidades, institutos tecnológicos e empresas, a qual contempla diversos mecanismos de apoio e estímulo à constituição de alianças estratégicas e ao desenvolvimento de projetos cooperativos entre universidades, institutos tecnológicos e empresas nacionais; e facilidades para que as ICT, possam compartilhar, mediante remuneração, seus laboratórios, instalações, infraestrutura e recursos humanos com empresas, seja para atividades de pesquisa conforme a situação especificada na lei.

A segunda vertente diz respeito ao estímulo à participação de instituições de ciência e tecnologia no processo de inovação, que faculta as ICT celebrar contratos de transferência de tecnologia e de licenciamento de patentes de sua propriedade, prestar serviços de consultoria especializada em atividades desenvolvidas no âmbito do setor produtivo, assim como estimular a participação de seus funcionários em projetos onde a inovação seja o principal foco. Além disso, determina que cada ICT constitua um Núcleo de Inovação Tecnológica (NIT) próprio ou em associação com outras ICT. Os pesquisadores vinculados às ICT, quando envolvidos nas atividades de prestação de serviços empreendidas por suas instituições, poderão, em casos específicos, beneficiar-se do resultado financeiro dos serviços prestados. Também faculta os servidores públicos das ICT, a receber, como estímulo à inovação, bolsa diretamente de instituição de apoio ou de agência de fomento.

A terceira vertente trata do incentivo à inovação na empresa que visa estimular uma maior contribuição do setor produtivo em relação à alocação de recursos financeiros na promoção da inovação. Também prevê a concessão, por parte da União, das ICT e das agências de fomento, de recursos financeiros, humanos, materiais ou de infraestrutura, para atender às empresas nacionais envolvidas em atividades de pesquisa e desenvolvimento, sendo que os recursos financeiros poderão vir sob a forma de subvenção econômica, financiamento ou participação societária. Contempla, ainda, apoio à realização de atividades de pesquisa e desenvolvimento, que envolvam risco tecnológico, para solução de problema técnico específico ou obtenção de produto ou processo inovador, assim como a implementação pelas agências de fomento, de programas com ações dirigidas especialmente à promoção da inovação nas micro e pequenas empresas.

Matias-Pereira e Kruglianskas (2005) afirmam que os propósitos da Lei de Inovação Tecnológica envolvem três principais eixos: a construção de ambiente propício a parcerias 
estratégicas entre as universidades, institutos tecnológicos e empresas; o fomento à participação de instituições de ciência e tecnologia no processo de inovação e o incentivo à inovação na empresa. Esses três eixos, segundo os autores envolvem bolsa de estímulo à inovação e pagamento ao servidor público de adicional variável não incorporável à remuneração permanente, a partir de recursos captados pela própria atividade, participação nas receitas auferidas pela instituição de origem com o uso da propriedade intelectual e a licença não remunerada para a criação de empresa de base tecnológica. O conceito de inovação, na Lei, é compreendido como "introdução de novidade ou aperfeiçoamento no ambiente produtivo ou social que resulte em novos produtos, processos ou serviços" (Brasil, 2011). Assim para Borges (2015), o foco da pesquisa científica é a geração de conhecimento e de tecnologias passíveis de serem aplicadas em processos de produção de produtos ou serviços.

Sendo assim, a questão consiste na produção de pesquisa que possa resultar em novos produtos possíveis de serem explorados social e economicamente. A prioridade, dessa forma, constitui-se na produção de conhecimento na universidade em termos de inovação tecnológica da educação superior brasileira: a Lei de Inovação Tecnológica e da Parceria Público-Privada (Borges, 2015).

Fujino e Stal (2004), em uma pesquisa sobre a gestão da propriedade intelectual realizada na universidade pública brasileira, verificaram que as maiores dificuldades para a colaboração entre empresa e universidade podem ser reunidas em duas categorias. A primeira trata das diferentes interpretações da lei da propriedade industrial de 1996. A segunda categoria, refere-se à cultura organizacional das universidades, baseada em valores ideológicos que não vão ao encontro de uma parceria empresarial. Simultaneamente, as universidades públicas pretendem aumentar a sua contribuição para o desenvolvimento tecnológico nacional, tendo em vista a Lei de Inovação.

Entretanto, a universidade brasileira, ao que tudo indica, ainda parece pouco ligada às necessidades da sociedade e longe de criar um sistema de inovação que consiga de fato, interligar e associar os diferentes atores e setores que compõem este sistema: governo, empresas e universidades (Schwwarzman, 2008).

Nesse sentido, a Lei da Inovação Tecnológica parece ser um tema de interesse e de discussão tanto no contexto empresarial como no acadêmico. Visando identificar os 
benefícios e desventuras da Lei de Inovação em pequenas empresas de base tecnológica, Garnica e Junged (2009) trazem importantes contribuições. Os autores constatam que apesar do avanço do governo em relação a legislação e a preocupação em propor a inovação no ambiente produtivo, parece que seus efeitos só poderão ser percebidos a partir de uma estruturação nas universidades para implementar sua cooperação com empresas e também por meio de uma mudança cultural no modo como são conduzidas pesquisas conjuntas.

O estudo de Matias-Pereira e Kruglianskas (2005) também evidenciou alguns desafios no que se refere à implementação da Lei da Inovação Tecnológica. Para os autores, sua aprovação não é suficiente para mudar a realidade atual nesse campo, sendo necessário ainda um maior envolvimento e compromisso dos agentes envolvidos. Os autores também constatam a carência de mecanismos que permitam a sua efetiva integração com as políticas industrial e tecnológica, a falta de flexibilidade de gestão das instituições de pesquisa e também a necessidade de um maior detalhamento da Lei, para preservação da identidade tanto das universidades quanto das indústrias e empresas, e assim tornar-se um instrumento relevante de fomento às políticas industrial e tecnológica do país.

\section{Método do Estudo}

Com o intuito de identificar os reflexos da Lei da Inovação Tecnológica em uma universidade federal do estado do Rio Grande Sul (RS), a abordagem deste estudo caracterizase como qualitativo. Conforme Richardson (1999), geralmente as investigações que se voltam para uma análise qualitativa têm como objeto situações complexas ou estritamente particulares, como é o caso da aplicabilidade da lei da inovação em uma universidade.

Quanto a sua natureza o estudo se configura do tipo exploratório. Para Malhotra (2006), o estudo exploratório possibilita a compreensão do problema enfrentado pelo pesquisador e a pesquisa qualitativa garante uma melhor visão e compreensão do contexto do problema.

Como fonte de coleta de dados foram utilizadas entrevistas semiestruturadas com os dirigentes da Universidade e responsáveis pela Agência de Inovação e Transferência de Tecnologia, além de análise de documentos e do site institucional. A coleta de dados foi realizada entre os meses de maio e junho de 2016. 
O roteiro foi desenvolvido com base na revisão da literatura, tendo como orientação os objetivos propostos pelo estudo, visando identificar os principais reflexos e efeitos da Lei da Inovação na Universidade, bem como as principais dificuldades e as oportunidades geradas, a partir dela. Foram entrevistadas quatro pessoas, sendo uma em cargo de direção em órgão da Universidade e três entrevistados responsáveis pela Agência de Inovação e Transferência de Tecnologia.

As entrevistas foram gravadas e transcritas e a análise delas foi desenvolvida por meio da análise de conteúdo. De acordo com Bardin (1977, p. 42) a análise de conteúdo é "um conjunto de técnicas de análise das comunicações visando obter, por procedimentos, sistemáticos e objetivos de descrição do conteúdo das mensagens, indicadores (quantitativos ou não) que permitam a inferência de conhecimentos relativos às condições de produção/recepção (variáveis inferidas) destas mensagens". Dessa forma, a análise de conteúdo foi realizada a partir de categorias definidas a posteriori, com base na revisão da literatura e nas entrevistas realizadas, que tratam do propósito da lei da inovação e das principais ações na Universidade; dos principais benefícios decorrentes da lei da inovação; e das principais dificuldades; bem como do conhecimento referente à lei da inovação.

Será apresentada, a seguir, a discussão dos resultados da pesquisa com os responsáveis pelos segmentos envolvidos no contexto da Lei da Inovação na determinada Universidade Federal.

\section{Apresentação e Análise dos Resultados}

A discussão dos resultados encontra-se dividida em quatro categorias: a primeira categoria se refere às ações desenvolvidas na Universidade Federal, decorrida da Lei da Inovação bem como seu principal propósito. A segunda categoria está relacionada aos benefícios que a Lei da Inovação trouxe para a Universidade, a terceira categoria se refere as principais dificuldades envolvendo a Lei da Inovação e por fim a quarta categoria se refere ao conhecimento da existência da Lei da Inovação.

A primeira categoria buscou identificar a percepção dos entrevistados no que se refere ao objetivo da Lei da Inovação e também e em relação a sua visão das principais ações que vêm sendo implementadas decorrentes da Lei da Inovação. O Quadro 1 apresenta as principais evidências. 
Quadro 1. Propósito da lei da inovação e principais ações na Universidade.

\begin{tabular}{|c|c|}
\hline Entrevistado & Evidências \\
\hline Entrevistado 1 & $\begin{array}{l}\text { "A universidade já tinha algumas ações isoladas antes mesmo da Lei de } \\
\text { Inovação [...] a própria criação da incubadora em 1995, contempla a Lei da } \\
\text { inovação. Depois da Lei da Inovação a gente tem que a criação do NIT } \\
\text { aqui dentro da Universidade. A gente tem também, depois disso, em } 2013 \\
\text { a criação do polo de inovação que é uma iniciativa de tentar fechar o ciclo } \\
\text { de inovação e criação de empresas, que é a incubadora, polos e parques } \\
\text { tecnológicos. Antes de } 2013,2012 \text { foi criado o Parque Tecnológico que é } \\
\text { uma iniciativa da universidade que trouxe recursos para a cidade e essa } \\
\text { parceria foi feita junto com a prefeitura e com entidades empresariais". }\end{array}$ \\
\hline Entrevistado 2 & $\begin{array}{l}\text { "A Incubadora Tecnológica já estava toda criada previamente à lei. Porém, } \\
\text { temos o projeto de um habitat de inovação maior, e a nova lei da inovação } \\
\text { vai acarretar que esse habitat vai ser muito mais atrativo pois irá facilitar a } \\
\text { relação universidade-empresa, irá quebrar alguns tabus e trâmites } \\
\text { burocráticos poderão ser agilizados" } \\
\text { "A Agência de Inovação e Transferência de Tecnologia foi criada antes da } \\
\text { Lei da Inovação e eu não estava presente quando ela foi projetada, mas } \\
\text { estive a partir de sua aprovação, que foi muito em razão da visão } \\
\text { estratégica de que a universidade precisa se aproximar das empresas e } \\
\text { vice/versa. Foi muito mais em razão dessa visão estratégica do que da } \\
\text { própria lei, mas claro que a Lei da Inovação facilitou a criação da } \\
\text { Agência". }\end{array}$ \\
\hline Entrevistado 3 & $\begin{array}{l}\text { "Fortalecimento das relações universidade-empresa via transferência de } \\
\text { tecnologia, convênios e contratos. Também se percebe o fortalecimento de } \\
\text { projetos de P\&D entre universidade-empresa". }\end{array}$ \\
\hline Entrevistado 4 & $\begin{array}{l}\text { "[...] fortalecer na universidade o ensino e a pesquisa, fundamentalmente a } \\
\text { extensão universitária, e, por outro, propiciar para as empresas o porte de } \\
\text { novas tecnologias. Para que assim tenhamos realmente desenvolvimento } \\
\text { de pesquisas brasileiras e que não seja importada toda a ciência de fora, } \\
\text { como é hoje a realidade brasileira". } \\
\text { "Hoje dentro da Universidade a Lei da Inovação está nos permitindo criar } \\
\text { novos mecanismos seja aumentada a relação da Universidade com as } \\
\text { empresas e com a sociedade, fazendo com que traga mais o papel de } \\
\text { universidade em prol do desenvolvimento brasileiro. Sem dúvidas a lei } \\
\text { também trouxe mecanismos que antes nós (universidade) não tínhamos e, } \\
\text { principalmente, clareou os mecanismos que utilizávamos já que muitas } \\
\text { vezes não tínhamos leis que suportassem esses mecanismos de } \\
\text { cooperação". }\end{array}$ \\
\hline
\end{tabular}

Fonte: Resultados da pesquisa.

Os entrevistados, de maneira geral, destacam que a Lei da Inovação tem como propósito principal fortalecer a relação entre universidade e as empresas privadas, por meio do desenvolvimento de novas tecnologias e da transferência dessas tecnologias para as empresas.

Essa integração parece ser fundamental para o surgimento dos chamados habitats de inovação, compostos por uma sinergia oriunda dos atores envolvidos como, instituições de ensino e pesquisa, empresas, governos e entidades representativas. Os propósitos 
evidenciados pelos entrevistados, parecem estar de acordo com as contribuições de Borges (2015) e Matias-Pereira e Kruglianskas (2005), já que eles afirmam que a lei tem como objetivo desenvolver um ambiente estratégico de geração de conhecimento e de tecnologias passíveis de serem aplicadas na produção de bens e serviços em empresas.

Quanto as principais ações implementadas a partir da Lei da Inovação, os entrevistados afirmam que existiam algumas práticas isoladas de inovação anterior à Lei, como a criação da Incubadora Tecnológica. No entanto, surgiram iniciativas que foram facilitadas a partir da Lei da Inovação, como a criação de um Parque Tecnológico e da Agência de Inovação e Transferência de Tecnologia. Ainda, destaca-se como principal ação o aumento da relação universidade-empresa, que trouxe novos mecanismos de cooperação para as universidades, refletindo também no fortalecimento projetos de P\&D.

A próxima categoria de análise apresenta os principais benefícios percebidos pelos entrevistados decorrentes da implementação da Lei da Inovação na Universidade, conforme apresentado no Quadro 2.

Quadro 2. Principais Benefícios decorrentes da lei da inovação.

\begin{tabular}{|c|c|}
\hline Entrevistado & Evidências \\
\hline Entrevistado 1 & $\begin{array}{l}\text { "Eu acho que a lei abriu os olhos das universidades de que há possibilidade de } \\
\text { um pesquisador inserir a sua pesquisa ou inovação no mercado, então abriu } \\
\text { essa possibilidade [...]". } \\
\text { "Aumentou, também, a visão das empresas da região pela possibilidade de } \\
\text { parceria com a Universidade e o aumento dessas parcerias, mas ainda há um } \\
\text { crescimento muito pequeno [...]". }\end{array}$ \\
\hline Entrevistado 2 & $\begin{array}{l}\text { "Ainda estamos fazendo os contratos e vamos conseguir ver um efeito } \\
\text { somente nos próximos dois anos, mas já imaginamos quais serão". }\end{array}$ \\
\hline Entrevistado 3 & $\begin{array}{l}\text { "A Lei da Inovação facilitou essas relações, uma vez que reduziu a burocracia } \\
\text { e ampliou o escopo onde as interações universidade-empresa são possíveis". }\end{array}$ \\
\hline Entrevistado 4 & $\begin{array}{l}\text { "São muitos os aspectos positivos. Temos dois cenários na universidade, } \\
\text { principalmente a Lei da Inovação junto com o surgimento da agência de } \\
\text { inovação, antes denominado NIT (que não tinha corpo suficiente para fazer } \\
\text { todas as ações). A agência de inovação da Universidade veio e trouxe corpo } \\
\text { suficiente. Hoje temos uma equipe grande e engajada trabalhando em prol da } \\
\text { inovação na universidade, do empreendedorismo, da transferência tecnológica } \\
\text { e da propaganda intelectual, então esse cenário do surgimento da agência } \\
\text { junto com a lei com certeza trouxe muitos benefícios para a universidade e } \\
\text { melhorou as nossas relações externas [...]". }\end{array}$ \\
\hline
\end{tabular}

Fonte: Resultados da pesquisa.

Observa-se que na visão dos entrevistados os principais benefícios que a Lei da Inovação trouxe foi a maior interação entre o meio acadêmico com o empresarial, reduziu 
também burocracias que dificultavam a existência dessa interação. Outro benefício identificado foi a expansão do Núcleo de Inovação Tecnológico (NIT), surgindo assim a agência de inovação da Universidade que vem atuando no processo de transferência de tecnologia desenvolvida na instituição para as empresas, do fomento do empreendedorismo e da propaganda intelectual. Ressalta-se que em razão da Coordenadoria de Empreendedorismo ainda estar firmando suas ações e parcerias, o "Entrevistado 3", não evidenciou benefícios imediatos, mas afirma vislumbrar a longo prazo benefícios concretos. Nesse sentido parece que as evidências encontradas corroboram com as contribuições de Machado e Rupphental (2014), uma vez que para os autores a implementação da Lei de Inovação deve levar à melhoria e ao aperfeiçoamento das atividades das Incubadoras Tecnológicas e, consequentemente, facilitar as parcerias público-privadas e a transferência de tecnologia.

No Quadro 3 apresenta-se a percepção dos entrevistados no que se refere às principais dificuldades encontradas em relação a Lei da Inovação.

Quadro 3. Principais dificuldades.

\begin{tabular}{|l|l|}
\hline \multicolumn{1}{|c|}{ Entrevistado } & \multicolumn{1}{c|}{ Evidências } \\
\hline \multirow{5}{*}{ Entrevistado 1 } & $\begin{array}{l}\text { "[...] porque a lei da inovação ainda tem muita diferença e discrepância com outras } \\
\text { leis. A gente tem as leis, a LDB, enfim outras leis que regulamentam tanto a ação } \\
\text { do docente em relação ao ensino superior tanto em relação às leis trabalhistas, então } \\
\text { a lei da inovação teve boa iniciativa, mas ainda não superou essas outras leis. Um } \\
\text { exemplo que eu dou: um docente hoje com dedicação exclusiva é impedido de } \\
\text { trabalhar em qualquer outra empresa, ele pode ser no máximo sócio, ele não pode } \\
\text { nem ser gerente nem nada. Só que tem as questões do docente ser inventor ou } \\
\text { propor uma inovação tecnológica que vai ter um trabalho específico. Para isso tem } \\
\text { que fazer um convênio, tem que ter uma pesquisa e ser feita dentro dos moldes da } \\
\text { universidade que vai ter repercussão dentro da empresa [...]. Então, ainda há } \\
\text { barreiras legais que precisam ser passadas pela lei. }\end{array}$ \\
\hline "Ainda temos algumas dúvidas acerca da operacionalização dela e de vetos que \\
ainda devem ser votados [...]".
\end{tabular}

Fonte: Resultados da pesquisa

Quanto as principais dificuldades envolvendo a Lei da Inovação na Universidade Federal, os entrevistados parecem apontar para aspectos relacionados a sua operacionalização. 
Destacam-se ainda algumas barreiras legais em relação ao envolvimento de docentes com empresas privadas e também as questões ideológicas dos diferentes indivíduos. Esse último fator parece estar em consonância com Maçonetto (2010), o qual evidencia que há ainda por parte de pesquisadores das instituições, certo receio, pelo medo de tornar a universidade muito utilitária, focada exclusivamente para o setor produtivo.

No entanto, estas dificuldades parecem ser importantes para a reflexão e a evolução no processo de inovação tecnológica.

A última categoria de análise buscou verificar a percepção dos entrevistados sobre o conhecimento referente a Lei da Inovação (Quadro 4).

\begin{tabular}{|c|c|}
\hline Entrevistado & Evidências \\
\hline Entrevistado 1 & $\begin{array}{l}\text { "Falta um trabalho, assim, de esclarecimento sobre os benefícios da lei. Tem alguns } \\
\text { professores que têm conhecimento, mas não investem. Vou dar um motivo bem } \\
\text { claro. A lei, até se você for ler e ver, vem tentar diminuir aquela visão tão acadêmica } \\
\text { da universidade que é produzir paper e produzir inovação, só que inovação a gente } \\
\text { sabe que é quando chega no mercado e traz algum benefício para a sociedade, isso é } \\
\text { inovação senão não é inovação, é invenção que ficou na prateleira. Só que para } \\
\text { romper com os papers você tem que conversar com a Capes de não exigir tanto dos } \\
\text { professores a produção senão o professor fica tão atrelado na sua progressão } \\
\text { funcional e tão atrelado no seu conceito de curso ou buscar mais recurso } \\
\text { extraorçamentários que para ele tem que produzir paper. Inovação para ele não é algo } \\
\text { tangível, que dê benefícios. Então, você fica preso, na verdade os professores são } \\
\text { escravos dessa filosofia enquanto que se explora pouco o benefício da inovação que o } \\
\text { professor poder ter, por esses receios: dedicação exclusiva, contatar Fatec e também } \\
\text { por falta de esclarecimento em relação aos benefícios que pode ter." }\end{array}$ \\
\hline Entrevistado 2 & $\begin{array}{l}\text { "Com certeza falta, a grande maioria ainda não tem conhecimento, até nós que } \\
\text { trabalhamos no órgão fim da lei ainda temos algumas dúvidas acerca da } \\
\text { operacionalização dela e de vetos que ainda devem ser votados. Se nós ainda temos } \\
\text { algumas dúvidas, imagina quem não trabalha com isso no dia a dia" }\end{array}$ \\
\hline Entrevistado 3 & "De uma forma geral a comunidade não conhece a Lei da inovação". \\
\hline Entrevistado 4 & $\begin{array}{l}\text { "Alguns professores, aqueles que mais estão ligados a projetos de pesquisas e já estão } \\
\text { nessa área há anos, principalmente projetos hoje operacionalizados via fundação de } \\
\text { apoio (que operacionaliza os projetos de inovação na universidade), estão mais } \\
\text { preocupados com isso, mas acredito que a grande maioria não. O que nós estamos } \\
\text { tentando fazer agora... é criar um cenário, criar eventos, palestras e toda essa } \\
\text { dinâmica para que mais pessoas estejam engajadas e tenham o conhecimento pleno } \\
\text { da lei da inovação" }\end{array}$ \\
\hline
\end{tabular}

Fonte: Resultados da pesquisa.

De modo geral, todos os entrevistados convergem quanto a carência de conhecimento e informação a respeito da Lei da Inovação na comunidade e entre os docentes. Conforme as evidências, a falta desse conhecimento dos docentes pode ser influenciada pela questão da 
dedicação exclusiva que possuem, pela exigência de produção científica do sistema e também pela falta de percepção em relação aos benefícios que a Lei da Inovação pode proporcionar.

Nessa perspectiva, Garnica e Jugned (2009) afirmam em seu estudo que um efetivo aproveitamento da pesquisa realizada pelas universidades em empresas passa por uma reestruturação de incentivos aos pesquisadores acadêmicos com essa finalidade, a qual não é tarefa simples, nem tampouco foi tratada pela Lei.

Entretanto, parece que a instituição está trabalhando em prol da disseminação desse conhecimento por meio de eventos, palestras, buscando solidificar as informações referentes à Lei da Inovação.

\section{Considerações Finais}

A regulamentação da Lei da Inovação parece ser uma importante ferramenta na busca do desenvolvimento das instituições e no desenvolvimento de soluções inovadoras para a sociedade. Desse modo, este estudo teve como objetivo central identificar os reflexos da Lei da Inovação em uma universidade federal do estado do Rio Grande do Sul (RS), contribuindo também para a discussão teórica da temática.

De modo geral, os resultados evidenciaram que os entrevistados reconhecem os propósitos da Lei da Inovação na Universidade, bem como seus benefícios e desafios no que tange à esfera pública e privada. Os entrevistados percebem a partir da regulamentação da Lei, um fortalecimento da interação entre universidade e empresas, a facilitação nos processos de parceria, fazendo com que o conhecimento científico gerado nas universidades resulte em novas tecnologias para o desenvolvimento de produtos e serviços nas empresas.

Apesar da importância atribuída à Lei da Inovação, os entrevistados percebem que ainda há dúvidas em relação a sua operacionalização e algumas divergências ideológicas em relação a interação entre universidades e empresas. Além disso, ainda é necessária a propagação do conhecimento da Lei da Inovação entre os docentes da universidade federal e comunidade em geral, pois é por meio da informação que se pode evoluir em direção ao desenvolvimento da inovação. Assim parece fundamental que os órgãos responsáveis pela gestão da inovação na universidade continuem concentrando esforços na divulgação dos propósitos e benefícios que a Lei da Inovação possibilita aos envolvidos. 
Observa-se também que mesmo estando em processo de expansão tanto no que se refere a ideologias e infraestruturas, a forma como está sendo conduzida a Lei da Inovação na universidade federal parece estar de acordo com os propósitos que a Lei busca alcançar. Acredita-se que apesar de não se ter, ainda, grandes ações consolidadas, há boas estimativas no que se refere ao desenvolvimento de inovação tecnológica e a transferência desta para o setor produtivo.

O estudo apresenta limitações relacionadas ao escopo de pesquisa dos tópicos propostos. As análises baseiam-se apenas na percepção dos entrevistados na instituição; sendo assim, os dados são restritos a este cenário específico.

Para estudos futuros, sugere-se analisar os efeitos da Lei da Inovação nas demais universidades do Rio Grande do Sul, buscando identificar se há similaridades de percepções e de ações desenvolvidas. Nesse sentido, seria possível evidenciar se as dificuldades percebidas a respeito da implementação e difusão da Lei da Inovação são restritas a determinada universidade federal ou se são problemas enfrentados pela maior parte das universidades.

\section{Referências}

Bardin, L. (1977). Análise de conteúdo. Lisboa: Edições 70.

Bergerman, M. (2005). Inovação como instrumento de geração de riqueza no Brasil: o exemplo dos institutos privados de inovação tecnológica. Seminários temáticos para a 3 a Conferência Nacional de CT\&I, Parcerias Estratégicas.

Borges, M. C. A. de. (2015). Educação e pesquisa. São Paulo, 41 (4), pp. 961-973.

Braga, C. S. C. \& Filho, J. C. L. da. S. (2014). Leis complementares à Lei de Inovação Federal: impacto sobre o desempenho inovativo dos estados. In: Encontro da Anpad, 38, 2014. Rio de Janeiro. Anais... Rio de Janeiro.

Brasil. (2011). Constituição da República Federativa do Brasil de 1988. Recuperado em 5 de setembro, 2011 , de http://www.planalto.gov.br/ccivil_03/Constituicao/Constituicao.htm.

Brasil. (2011). Lei no 10.973, de 2 de dezembro de 2004. Dispõe sobre incentivos à inovação e à pesquisa científica e tecnológica no ambiente produtivo. Recuperado em 28 de julho, 2011, de http://www.planalto.gov.br/ccivil_03. 
Etzkowitz, H. (2005). Reconstrução criativa: hélice tripla e inovação regional. Revista Inteligência Empresarial. Centro de Referência em Inteligência Empresarial. Crie/Coppe/UFRJ. Número 23 - abr./maio/jun. 2005.

(2009). Hélice Tríplice: Universidade-Indústria-Governo - Inovação em Movimento (1a ed.). Porto Alegre: EDIPUCRS.

Etzkowitz, H. \& Spivack, R. N. (2001). Networks of Innovation: science, technology and development in the triple helix era. International Journal of Technology Management and Sustainable Development. vol.1, n.1, pp.7-20.

Etzkowitz, H. \&Webster, A. (1998). Entrepreneurial Science: The Second Academic Revolution. In: Etzkowitz, H. \& Webster, A. Capitalizing knowledge: new intersections of industry and academia. Albany: State University of New York Press.

Fujino, A. \& Stal, E. (2004) Gestão da propriedade intelectual na universidade pública brasileira: diretrizes para licenciamento e comercialização. In: Simpósio de Gestão da Inovação Tecnológica, 23, 2004, Curitiba. Anais... São Paulo: FEA/USP, 1 CD-ROM.

. (2005). As relações universidade-empresa no Brasil sob a ótica da Lei de Inovação. In: RAI - Revista de Administração e Inovação, São Paulo, vol. 2, n. 1, pp. 5-19.

Fujino, A., Stal, E. \& Plonski, G. A. (1999). A proteção do conhecimento na universidade. Revista de Administração, São Paulo, vol. 34, n. 4, pp. 46-55, out./dez.

Garnica, L. A., \& Jugend, D. (2009). Estímulo à inovação em empresas de base tecnológica de pequeno porte: uma análise da lei federal brasileira de inovação. Revista da Micro e Pequena Empresa, Campo Limpo Paulista, vol.3, n.1, pp.82-98.

Gubiani, S. J. (2011). Modelo para diagnosticar a influência do capital intelectual no potencial de inovação nas universidades. 2011. Tese de Doutorado em Engenharia e Gestão do Conhecimento), Curso Programa de Pós-graduação em Engenharia e Gestão do Conhecimento, Universidade Federal de Santa Catarina, Florianópolis.

Machado, F. M., \& Rupphental, J. E. (2014). Estudos dos pontos de conflito da Lei de Inovação. International Journal of Knowledge Engineering, vol. 3, n. 6, pp. 230-245.

Malhotra, N. K. (2006). Pesquisa de Marketing: uma orientação aplicada (4a ed.). Porto Alegre: Bookman.

Matias-Pereira, J. M., \& Kruglianskas, I. (2005). Gestão de inovação: a Lei de Inovação Tecnológica como ferramenta de apoio às políticas industrial e tecnológica do Brasil. RAE- eletrônica, vol. 4, n. 2, art. 18. 
Maçonetto, M. R. (2010). Políticas públicas em inovação. Um estudo comparativo entre as estratégias empegadas no Programa de Inovação Tecnológica (PIT) e no Programa de Primeira Empresa Inovadora (PRIME). Dissertação de Mestrado em Administração. Programa de Pós-graduação em Administração de Organizações, Universidade de São Paulo, Ribeirão Preto.

Ministério da Ciência, Tecnologia e Inovação. (2016). Marco Legal da Inovação. Recuperado em 12 de junho, 2016, de http://www.mct.gov.br/index.php/content/view/8477.html.

Nelson, R. R. (Ed.). (1993). National innovation systems: a comparative analysis. New York: Oxford University Press.

Neto, R. N. (2005). Regionalização de C\&T e geração de riqueza. Seminários temáticos para a $3^{a}$ Conferência Nacional de C, T\&I, Parcerias Estratégicas - n. 20, 2005.

Pacheco, E. R. M. de (2010). Mapeamento do fomento à inovação tecnológica no Brasil. Rio de Janeiro. Dissertação de Mestrado. Centro Federal de Educação Tecnológica Celso Suckow da Fonseca, Rio de Janeiro.

Patel, P. \& Pavitt, K. (1994). National innovation systems: why they are important, and how they might be measured and compared. Economics of Innovation and New Technology, Abingdon, vol. 3, n. 1, pp. 77-95.

Plonski, G. A. (1995). Cooperação empresa-universidade: antigos dilemas, novos desafios. Revista USP: Dossiê Universidade-Empresa, São Paulo, vol. 25, pp. 32-41.

Plonski, G. A. (2005). Bases para um movimento pela inovação tecnológica no Brasil. São Paulo em Perspectiva, vol. 19, n. 1, pp. 25-33.

Reis, D. R. (2004). Gestão da Inovação Tecnológica. Barueri: Manole.

Richardson, R. J. (1999). Pesquisa social: métodos e técnicas (3a ed.). São Paulo: Atlas.

Sbragia, R., \& Stal, E. (2004). A empresa e a inovação tecnológica: motivações, parcerias e papel do estado. Fórum de Líderes, Belo Horizonte, vol. 11, pp. 6-14, nov.

Schwwarzman, S. (2008). Pesquisa universitária e inovação no Brasil. Centro de Gestão e Estudos Estratégicos, Ciência, Tecnologia e Inovação.

Serzedello, N. T. B. \& Tomaél, M. I. (2011). Produção tecnológica da Universidade Estadual de Londrina (UEL): Mapeamento da área de Ciências Agrárias pela Plataforma Lattes. AtoZ: Novas Práticas em Informação e Conhecimento, vol. 1, n. 1, pp. 23-37. 
Viale, R. \& Etzkowitz, H. (2005). Third academic revolution: polyvalent knowledge, The "DNA" of the Triple Helix." in Triple Helix 5. Turin, Italy. 